\title{
RODAS DE CONVERSA NA UNIVERSIDADE PÚBLICA DURANTE A PANDEMIA COVID-19: EDUCAÇÃO E SAÚDE MENTAL
}

\author{
Andrés Eduardo Aguirre Antúnez ${ }^{1}$ \\ Instituto de Psicologia da Universidade de São Paulo (IPUSP) \\ Ana Luiza Raggio Colagrossi \\ Departamento de Psicopedagogia, Instituto Sedes Sapientiae, SP \\ Erika Rodrigues Colombo ${ }^{3}$ \\ Instituto de Psicologia da Universidade de São Paulo (IPUSP) \\ Frida Zolty ${ }^{4}$ \\ Instituto de Psicologia da Universidade de São Paulo (IPUSP) \\ Nara Helena Lopes Pereira da Silva ${ }^{5}$ \\ Instituto de Psicologia da Universidade de São Paulo (IPUSP)
}

\section{RESUMO}

Desde o início da pandemia Covid-19, o Escritório de Saúde Mental da Pró-Reitoria de Graduação da USP tem oferecido acolhimentos, pesquisas e ações de promoção a saúde de estudantes de graduação e pós-graduação, mediados pelas tecnologias digitais. Dentre as modalidades oferecidas, a Roda de Conversa tem como foco a abordagem socioemocional e pretende sensibilizar, construir e fortalecer redes de apoio entre estudantes, professores e funcionários e seu principal objetivo é acolher de forma ágil a demanda de ajuda decorrente dos problemas psicológicos e emocionais relacionados ao distanciamento físico. Diversas formas de interação e estratégias de mediação baseadas na construção de conhecimento a partir da experiência vivida foram utilizadas. A Roda de Conversa propicia o compartilhamento de ansiedades, medos e esperanças de seus participantes. Cada fala pode ser representativa de um sentimento grupal, mas também pode levar a diferenças e discordâncias que evidenciam a alteridade e é através desse espaço de diálogo, interação e reflexão que se busca estabelecer a conexão e a empatia. As Rodas de Conversa foram realizadas em seis Unidades de Ensino, atendendo-se às demandas específicas de cada uma delas: algumas apenas com estudantes de graduação e/ou pós-graduação, outras só com funcionários e outras envolvendo docentes e discentes. Os resultados mostram que as Rodas de Conversa possibilitam o compartilhamento de dificuldades comuns, promovem uma forma de comunicação colaborativa e fortalecem o vínculo entre os participantes favorecendo a

\footnotetext{
${ }^{1}$ Livre-Docência em Psicologia Clínica USP; Doutorado em Ciências UNIFESP.

2 Doutorado em Ciência Médicas IDOR. Mestre em Psicologia da Educação - NYU; Neuropsicopedagogia FACON e Pedagoga PUC/RJ.

${ }^{3}$ Psicóloga, doutoranda do Departamento de Psicologia Clínica do IPUSP.

${ }^{4}$ Psicóloga graduada no IPUSP.

${ }^{5}$ Psicóloga, pós-doutoranda do Departamento de Psicologia Clínica, IPUSP.
} 
experiência de pertencimento. Concluiu-se que as Rodas de Conversa podem ampliar o autoconhecimento em relação ao sofrimento vivido por meio da expressão verbal e das reflexões em grupo decorrentes.

Palavras-chave: Saúde mental, Educação, Universidade, Covid-19.

\section{CONVERSATION CIRCLE AT THE PUBLIC UNIVERSITY DURING COVID 19 PANDEMIC: EDUCATION AND MENTAL HEALTH}

\section{ABSTRACT}

Since the beginning of the Covid-19 pandemic, the Office of Mental Health of the Dean of Undergraduate Studies at USP has offered individual support session, research, and actions to promote the health of undergraduate and graduate students, mediated by digital technologies. Among the modalities offered, the Conversation Circles focuses on the socio-emotional approach and intends to raise awareness, build, and strengthen support networks among students, professors, and staff. The main objective is to respond quickly to the demand for help arising from psychological and emotional problems. related to physical distance. Several forms of interaction and mediation strategies based on the construction of knowledge from the lived experience were used. The Conversation Circle allows the sharing of anxieties, fears, and hopes of participants. Each testimonial can be representative of a group feeling, but it can also lead to differences and disagreements that show otherness and it is through this space of dialogue, interaction, and reflection that connection and empathy are sought. The rounds of conversation were held in six Teaching Units, meeting the specific demands of each one of them: some only with undergraduate and/or graduate students, others only with employees and others involving professors and students. The results show that Conversation Circles enable the sharing of common difficulties, promote a form of collaborative communication, and strengthen the bond between the participants, favoring the experience of belonging. It was concluded that the Conversation Circles can increase self-knowledge in relation to the suffering experienced through verbal expression and the resulting group reflections.

Keywords: Mental Health, Education, University, Covid-19.

\section{Introdução}

As Rodas de Conversa ${ }^{1}$ têm sido utilizadas como instrumento de trabalho no ambiente escolar por Warschauer (2004) desde 1993, tanto com alunos do Ensino Fundamental quanto com professores. Sua experiência mostra que elas se constituem como um caminho para o aprendizado da convivência, ao mesmo tempo que proporcionam a construção de conhecimentos de forma integrada e com sentido, permitindo aos alunos tornarem-se sujeitos do conhecimento.

As Rodas promovem, nos educadores, a reflexão individual e coletiva sobre o caráter processual da formação dos professores e da íntima relação com as histórias de vida de cada um, rompen-

\footnotetext{
A palavra "roda" remete ao movimento cíclico. Além disso, a etimologia da palavra "conversa" - do latim conversare, cuja raiz "verso" significa voltar, virar ou direcionar e o prefixo com (cum) significa "junto com" ou na companhia de alguém - remete à ideia de se voltar para junto de alguém.
} 
do-se assim com ciclos de reprodução da concepção de escola e de ensino vigentes e promovendo a construção de novos conhecimentos (WARSCHAUER, 2004).

Seguindo a mesma perspectiva, Moura e Lima (2014) conduziram Rodas de Conversa com professores universitários direcionadas pelas seguintes questões: "Como deve ser o professor do ensino superior?"; "Como soluciono as demandas da minha sala de aula, considerando que a atividade docente, mesmo sendo imprescindível de planejamento, é eivada de ineditismo e improvisação?"; "Quais as contribuições que recebemos para nossa atuação em sala de aula? Como a prática nos ajuda na atuação docente?” (p.102).

Em seus resultados e constatações os autores observaram que:

(...) o universo de atuação dos professores universitários é complexo e contempla aspectos de ordem interna e externa às instituições educacionais. É um ambiente marcado pelo signo da mudança e dos controles externos e internos e o trabalho do professor é constantemente avaliado por indicadores de várias ordens, exigindo deste profissional uma capacidade de adaptação e ocupação de espaços que antes não faziam parte de seu cotidiano. Ao professor do ensino superior é exigida a atividade de ensino, mas também a atividade de pesquisa e extensão, e que se adeque as tecnologias interativas da educação (MOURA; LIMA, 2014, p.172-173).

Conforme Arbex (2019, p.52), a Roda de Conversa: "É um exercício constante de observação e escuta do outro e de si próprio. Esperar a vez de falar e estar atento à fala do colega". Neste sentido, a abordagem socioemocional ${ }^{2}$, como forma de sensibilização, facilita o acoIhimento e construção de vínculos através do autoconhecimento, da resiliência emocional e da empatia.

Saindo do âmbito estritamente educacional, encontramos diversas iniciativas que utilizam as Rodas de Conversa como espaço de cuidado e promoção da saúde mental. Andrade et al (2020) realizaram Rodas de Conversa on-line para pais de crianças com autismo, buscando criar um espaço de escuta e partilha frente à angústia dessas famílias cujas rotinas foram drasticamente modificadas pela pandemia Covid-19.

Assis et al (2020) apresentam o trabalho do ABRACE em Casa, um grupo de acolhimento virtual para escuta e apoio emocional de estudantes da Universidade Federal de Ouro Preto durante a pandemia Covid-19. Borges et al (2020) descrevem a experiência com o projeto Conversa na rede - Rodas de Conversa realizadas na residência estudantil do Instituto Federal de Educação, Ciência e Tecnologia do Rio Grande do Sul, para tratar das experiências de vida dos alunos - que foi adaptado para encontros on-line, a partir da pandemia.

Inicialmente, as Rodas de Conversa foram implementadas e estudadas como um instrumento a ser utilizado na condução de estratégias de cuidado em saúde, principalmente no âmbito da saúde mental (COSTA et al, 2014). Tais experiências demonstraram que as Rodas possibilitam encontros dialógicos e criam possibilidades de produção e ressignificação de sentidos e saberes, uma vez que estão pautadas na horizontalização das relações de poder, permitindo a seus participantes se colocarem como atores históricos e sociais, críticos e reflexivos diante da realidade (SAMPAIO et al, 2014).

Na universidade pública, o sofrimento psicológico esteve em evidência em agosto de 2018, quando ocorreram quatro suicídios entre a comunidade universitária noticiados em jornais de

Termo relativo simultaneamente a questões sociais e emocionais. A aprendizagem Socioemocional é um "Termo abrangente para representar uma ampla gama de habilidades que os indivíduos precisam para definir metas, gerenciar comportamento, construir relações e lembrar informações" (EXPLORE SEL, 2020). 
grande circulação. Diante disso, mobilizações e discussões no ambiente universitário se intensificaram em busca de ampliar as possibilidades para o acolhimento estudantil.

A Universidade de São Paulo foi criada em 1934 e é mantida pelo Governo do Estado de São Paulo. De acordo com o Anuário Estatístico de 2020 conta com um total de 97.335 estudantes, 13.368 funcionários técnicos e administrativos e 5.383 docentes distribuídos em oito Campus (São Paulo, Bauru, Lorena, Piracicaba, Pirassununga, Ribeirão Preto, São Carlos e Santos). Entre as universidades públicas brasileiras é aquela que tem o maior número de vagas de graduação e pós-graduação.

O Escritório de Saúde Mental (ESM) teve sua origem em abril de 2018, dentre as ações da Pró-Reitoria de Graduação e em conjunto com dirigentes do Instituto de Psicologia e Instituto de Psiquiatria da Faculdade de Medicina, que refletiam sobre as possibilidades de acoIhimento estudantil (CRUZ, 2018). O objetivo é proporcionar aos estudantes de graduação e pós-graduação acolhimento em relação ao sofrimento psíquico apresentado durante a formação universitária através de uma equipe multidisciplinar, levando-se em conta as dimensões mental, emocional e social de cada indivíduo. Para isso, diversos projetos são oferecidos, dentre eles as Rodas de Conversa com servidores públicos (funcionários e professores) e alunos.

A porta de entrada do ESM acontece de forma assíncrona, através de contato por e-mail e preenchimento de um formulário on-line que recolhe dados iniciais do estudante, via site institucional. Prioriza-se o contato rápido de resposta por e-mail (atendendo a todos os requisitos necessários de segurança digital) e o estudante é encaminhado para acolhimento, realizado em até três encontros, feito por colaboradores do ESM - psicólogos formados. Por fim, aqueles que tiverem necessidade de um acompanhamento prolongado podem ser encaminhados para pesquisas realizadas em parceria com o Programa de Pós-graduação em Psicologia Clínica do Instituto de Psicologia.

A Pandemia Covid-19 e o distanciamento social trouxeram a necessidade de adaptação das diversas formas de cuidado no campo da saúde mental. Desde março de 2020, o Escritório de Saúde Mental passou a oferecer o atendimento psicológico através do uso das Tecnologias de Informação e Comunicação (TICs). Com a crescente demanda por aconselhamento dentre os gestores de algumas Unidades do campus, percebeu-se a importância de oferecer ações preventivas abrangentes, visando dar suporte aos funcionários e professores da universidade.

A partir dessa demanda, surge a proposta da realização de Roda de Conversa On-line como modalidade de atendimento em grupo. Originado no campo da educação, a Roda de Conversa é uma interação dinâmica que permite ao participante se manifestar em ambiente seguro. Consiste em um método de participação coletiva de debate que poderá ser de temática livre ou determinada e promove o diálogo e o exercício reflexivo através da fala, da própria escuta e da escuta de seus pares (MOURA; LIMA, 2014).

As Rodas oferecidas pelo ESM têm como foco a abordagem socioemocional para sensibilização, construção e fortalecimento de redes de apoio entre estudantes, professores e funcionários da USP. Seu principal objetivo é acolher de forma ágil a demanda de ajuda para questões psicológicas relacionadas ao distanciamento físico-social e suas consequências para a vida universitária.

Este trabalho visa apresentar as vivências relatadas por mediadores de Rodas de Conversa desenvolvidas na modalidade on-line e iniciadas durante a pandemia covid-19 em uma comunidade universitária. 


\section{Aspectos éticos}

O estudo descrito faz parte de um projeto maior que aborda diferentes modalidades de atendimento mediadas pelas novas Tecnologias de Informação e Comunicação (TIC's) em saúde mental no contexto da pandemia, que foi aprovado pelo Comitê da Universidade de São Paulo sob o parecer no 051165/2020; CAAE: 32288820.6.0000.5561.

\section{Método}

A amostra de participantes constitui-se num total de 250 estudantes de graduação e pós-graduação, professores e funcionários de qualquer gênero e idade. Como critério de inclusão são necessários o vínculo à Universidade de São Paulo e o acesso à internet, contando com algum dispositivo que possibilite a participação nos encontros.

Os encontros aconteceram no período de 31 de agosto de 2020 a 30 de março de 2021 e cada um teve duração de 90 minutos. Todos foram conduzidos por colaboradores do ESM, co-autores deste artigo, que atuaram como mediadores nos 26 encontros realizados. Cada Unidade seguiu um processo distinto de comunicação e convite para os participantes: e-mail da Unidade ou do próprio ESM.

\section{Contexto e Procedimentos}

Acolhimentos interpessoais no formato de consultas terapêuticas on-line (ANTÚNEZ; SILVA, 2021) já ocorriam desde o início da pandemia na modalidade online. A partir da pandemia, percebeu-se a necessidade do desenvolvimento de ações também para a promoção da saúde mental e de um trabalho preventivo que abarcasse funcionários e docentes, além dos estudantes.

A conversa com a equipe de colaboradores teve início em maio 2020, a partir da discussão sobre o livro e o aplicativo Mee Too (www.meetoo.help). O aplicativo tem a proposta de dar visibilidade à linguagem dos jovens, aos aspectos da saúde mental, imagem corporal, suicídio, gênero, automutilação e formas de autoexpressão através de suas vozes, desenhos, fotos, imagens, colagens e outras.

A estruturação das Rodas de Conversa apresentou-se, então, como uma possibilidade de acolher de forma ágil a demanda de ajuda diante dos problemas psicológicos e emocionais relacionados ao distanciamento físico e social causado pelo Covid-19. Tendo como premissa que a narrativa constrói compaixão - "encontramo-nos nos outros, na escutatória" (ALVES, 1991) - de modo que o jovem apoia o jovem.

As Rodas de Conversa aconteceram na modalidade on-line, através da plataforma Google Meet. A escolha da plataforma atende aos requisitos de segurança de dados, visto que é uma ferramenta que faz parte do convênio Google-USP, o que garante maior proteção dentro do domínio da universidade pública. Foram consideradas as condições individuais de cada participante, respeitando sua privacidade, sendo opcional o uso da câmera aberta.

As Rodas de Conversa On-Line foram registradas textualmente pelos facilitadores durante os encontros e, para a análise, dois eixos foram organizados de acordo com o perfil dos participantes:

a. Grupos homogêneos - aqueles com o mesmo perfil de participantes - incluindo: grupos com estudantes da graduação e da pós-graduação, grupos com professores e grupos com funcionários. 
b. Grupos heterogêneos - caracterizados pela participação de dois ou mais perfis - incluindo: grupos de professores e alunos, grupos de alunos e funcionários, grupos de alunos, professores e funcionários.

Os modelos de interação variaram de acordo com o grupo e a demanda da Unidade ou de seus participantes, podendo ser: tema aberto, temático ou expositivo com auxílio de recursos externos. Em todos os grupos, no primeiro encontro, era feita uma rodada de apresentação informal entre os participantes.

A abordagem socioemocional foi utilizada como ferramenta da dinâmica da Roda de Conversa visando facilitar a interação, seja através da apresentação de slides ou proporcionando reflexões pontuais estimuladas pelos mediadores. A participação dos mediadores tinha como objetivo facilitar o diálogo e, a partir do significado da palavra, ser um elo facilitador da comunicação.

\section{Resultados}

\section{Grupos homogêneos}

As temáticas abordadas foram definidas no próprio encontro a partir da interação entre participantes. Tanto entre os alunos de graduação como entre os da pós-graduação destacam-se a dificuldade de lidar com as exigências de produtividade - sentida como fonte geradora de estresse e ansiedades - e de organizar o tempo diante das cobranças de estudos, pesquisas, trabalho, demandas familiares e a perda de motivação.

Os estudantes relatam que durante as aulas, a maioria não abria suas câmeras e uma das razões para isso era a falta de privacidade no ambiente familiar. Como alternativa, o chat, do Google Meet, foi uma ferramenta bastante utilizada como forma de expressão e apoio aos colegas. Entre as queixas, comentam também sobre a falta de pausas durante as aulas, o que lhes permitiria um tempo para pensar, refletir e conversar entre si, mesmo que brevemente e têm preferência pelas aulas gravadas que podem ser assistidas a qualquer momento.

Também apareceram queixas em relação a dificuldades de adaptação à nova realidade trazida pela pandemia. Houve relatos de faltas excessivas nas aulas on-line, dificuldade de gestão de tempo e falta de oportunidades de estágio. A comunicação interpessoal em aula através da realidade virtual foi sentida como empobrecida, com perda da sensibilidade nas relações. Não houve queixas em relação aos conteúdos de ensino, mas sim, ao modo como se dão as relações no ambiente on-line.

Dentre as temáticas desenvolvidas estão: ingresso na universidade durante a pandemia, perdas de produtividade, solidão, perda de pessoas próximas e lutos não elaborados. Outras fontes de preocupação foram: a pouca adesão das pessoas em relação às medidas protetivas (como uso de máscaras), a perda de colegas e amigos de infância, as notícias médicas com orientações para não sair de casa e o cenário de saturação do sistema de saúde por conta do tratamento para a Covid-19.

Questões raciais e manifestações preconceituosas dentro da universidade também apareceram na fala dos alunos. Diante disso, alguns alunos questionavam-se sobre se a pós-graduação ainda seria o projeto de vida. A busca das atividades que priorizam a qualidade de vida apareceu como uma forma de enfrentamento dos sofrimentos nomeados. Aspectos como a importância da arte e das várias formas de expressões culturais foram abordados como forma de suavizar o isolamento. A abrangência dos tópicos discutidos sugere o alcance que as Rodas de Conversa podem ter. 
Estudantes que habitam o Centro Residencial da Universidade (CRUSP) tem Rodas de Conversas mensais, desenvolvidas em ações intersetoriais entre a Superintendência da Assistência Social e o Escritório de Saúde Mental da Pró-Reitoria de Graduação, como oportunidade de um diálogo diferenciado. Nessas Rodas, as questões que mais se evidenciam são os medos e ansiedades em relação ao futuro, a preocupação com a economia institucional e pessoal e a nova realidade híbrida entre o presencial e o remoto.

A importância das boas práticas alimentares, esportivas e culturais e do contato com pessoas próximas como forma de ajuda mútua apareceram nas conversas com estudantes que habitam na Universidade como uma forma de minorar as dificuldades, sofrimentos, desmotivação e tristezas. O sentimento de insegurança e a importância da comunicação entre os moradores, com a Superintendência de Assistência Social, com o Núcleo de Estudos da Violência e o Grupo Não-Cala do Instituto de Psicologia foram temas debatidos.

A partir de relatos sobre dificuldades psicológicas, transtornos e tentativas de suicídio, foi discutido o papel da psicoterapia como suporte possível para manter a saúde mental durante a pandemia.

O tema do isolamento apareceu com frequência, tanto no âmbito pessoal e familiar quanto no institucional, entre os alunos que têm pouco contato entre si na moradia estudantil. Através da fala pode-se resgatar a sensação de pertencimento e enraizamento em relação às suas famílias e culturas. Essa interação permitiu que estudantes que não se conheciam trocassem telefone para contato, evidenciando a formação de uma rede de apoio e solidariedade.

Em unidades da área da saúde, o interesse dos estudantes foi pelo tema da saúde mental, especialmente por estarem em contato com a prática na formação, o que envolve temores sobre o risco de serem contaminados ou contaminar seus familiares com Covid-19. Em algumas conversas surgiram sentimentos ambíguos que se referiam tanto ao medo do desconhecido e do invisível quanto da alegria pela retomada das atividades práticas. Nesta mesma unidade, foram feitas conversas iniciais e uma apresentação sobre o tema "cuidar de quem cuida", valorizando a importância de estar bem para acolher o outro.

Em uma Unidade da área de humanas, professores e funcionários se sentiram mais confortáveis em grupos homogêneos e ansiaram por oportunidades de se manifestar de forma livre. As Rodas de Conversa on-line possibilitaram que se tomasse conhecimento de certas vivências pessoais que no contato profissional e presencial não eram possíveis.

Alguns temas trazidos pelos funcionários, referente ao uso de recursos digitais durante o trabalho remoto: certos alunos ficaram "mais maduros" (sic), alunos mais jovens se adaptaram melhor e mais rápido, professores mais idosos tiveram maiores dificuldades com a utilização da tecnologia e com a interação virtual em si. Os próprios funcionários tiveram que se reorganizar quanto ao espaço, o tempo, e as novas formas de comunicação tecnológicas.

Nas rodas com funcionários, estes manifestaram aspectos positivos diante da pandemia tais como a diminuição do tempo despendido no trânsito, o que possibilitou maior produtividade e criou oportunidade de cuidarem de suas atividades físicas.

\section{Grupos heterogênios}

As temáticas abordadas nos grupos heterogêneos são semelhantes às dos grupos homogêneos. Entretanto, enquanto nos grupos homogêneos os integrantes compartilhavam de forma mais aberta e ampla seus sentimentos, nos grupos heterogêneos os professores e funcionários basicamente escutavam as colocações dos estudantes, trazendo reflexões sobre resiliência para enfrentar situações inusitadas. 
Em alguns casos, a presença de alunos, professores, funcionários e dirigentes da Unidade demonstrou a valorização do compartilhar vivências e experiências proporcionadas pelas Rodas de Conversa. A falta de atividades físicas e a necessidade de se organizar para manter a motivação foram dialogados com frequência entre os grupos e possibilitaram aos participantes terem novas ideias para o enfrentamento das situações vividas na pandemia.

Em uma das unidades, cinco encontros consecutivos ocorreram com a participação de professores e funcionários, com uma participação gradativa dos estudantes. Devido ao interesse dos participantes, a unidade transformou as Rodas de Conversa em uma atividade mensal, com data pré-definida, para se discutir a saúde mental durante a pandemia.

Nestes grupos, também aconteceu o modelo de interação expositiva com a utilização de recursos externos com a temática "Como me sinto nesta pandemia". Também se utilizou o recurso da nuvem de palavras ${ }^{3}$. A conversa foi sobre tristeza, estresse, sentir-se confuso, assustado e nervoso durante uma crise.

Motivados com a importância de debater sobre os estigmas e preconceitos que violam os direitos humanos e as angústias pessoais e grupais, em uma das unidades foi criado o Grupo de Saúde Mental (GSM), que repercutiu na criação de uma portaria cujo objetivos são:

(...) constituir-se em um canal aberto para servidores docentes, técnico-administrativos e estudantes buscarem ajuda no que se refere à acolhimento psicológico; constituir-se em um canal de interlocução com o Núcleo de Direitos Humanos da FCF/USP (NDH), a fim de acolher demandas do $\mathrm{NDH}$ relacionadas à saúde mental; promover atividades que fomentem o bem estar e a preservação da saúde mental dos docentes, dos servidores técnicos e administrativos e estudantes, como, por exemplo, Rodas de conversa; constituir-se em elo de ligação e direcionamento de indivíduos para o Escritório de Saúde Mental, conforme a disponibilidade deste em recebê-los. Constituir-se em elo de ligação e direcionamento de estudantes para o Escritório de Saúde Mental, conforme a disponibilidade deste em recebê-los e/ou organização de Rodas de conversa com estudantes, técnicos administrativos e professores com colaboradores do Escritório de Saúde Mental. (Portaria FCF-663, de 05-10-2020 Diário Oficial Poder Executivo - Seção I quarta-feira, 7 de outubro de 2020. São Paulo, 130 (199)).

A criação desta portaria, mostra um movimento na busca de estruturar de forma contínua a Roda de Conversa como forma de suporte aos estudantes, professores e funcionários.

\section{Discussão}

Os relatos de cada participante nas Rodas de Conversa não foram entendidos pelos coordenadores da atividade como apenas um desabafo porque existe um cuidado dos membros do ESM em relação a eles e entre todos, uma ação de solidariedade, cuidado e respeito mútuos, onde todos estão envolvidos neste momento. Nesse sentido as falas tecem uma experiência que é vivida com muito interesse por todos, diálogos que possibilitam inclusive a construção de redes entre os participantes, para além das Rodas de Conversa. Percebeu-se que a troca afetiva com colegas que nada conheciam um do outro foi um dos potenciais trazidos por este formato de intervenção.

As experiências compartilhadas geraram, nas Rodas de Conversa, a sensação de pertencimento a um grupo, a uma comunidade humana que pode sofrer e expressar seu sofrimento sem que

3 https://www.mentimeter.com/pt-BR/features/word-cloud 
isso seja considerado fraqueza ou deficiência, mas sim a possibilidade reativar potenciais de resiliência inerentes à condição humana em uma situação de pandemia. $O$ sentimento de pertencimento ocorre pela ação na relação inter-humana em grupo, onde cada pessoa pode se expressar - verbalmente ou no chat - e é respeitada, ouvida, considerada em sua dignidade, pessoalidade e ética mútuas, resgatando sua cidadania. Desta forma, a oportunidade de conversar sobre assuntos que tocaram a interioridade de cada participante possibilitou a expressão de assuntos que, via de regra também são vividos por outros, tornando o que parece pessoal uma experiência comum a muitos.

As expressões de cada um são consideradas não apenas como conteúdos únicos daquele que se expressa, mas como uma fala significativa de um grupo, de facetas importantes que constroem a experiência compartilhada. A participação de todos no debate com temática livre ou determinada promoveu a reflexão comunitária, tal como constataram Moura e Lima (2014) e modificou as relações de ensino entre aprendiz e mestre ou chefe e funcionário, constituindo um novo conhecimento do Outro através do sentimento, pensamento e vivências pessoais. (WARSCHAUER, 2004).

Essas ações em grupo no diálogo compartilhado livre e de construção de conversas são ações preventivas; aliviam angústias e possibilitam, ao ouvir outros componentes do grupo, a reflexão sobre si e o grupo. Cria-se um sentimento de não estar isolado, de que o seu sentimento é o sentimento de muitos e de que cada um faz parte de uma comunidade que procura algo que os une no enfrentamento das dificuldades, temores, medos, incertezas diante do invisível desta pandemia que ameaça a humanidade e o cotidiano, que alterou as relações de trabalho, de pesquisa, de ensino e relações sociais vigentes até fevereiro de 2020.

Observou-se que cada participante, ao ouvir com atenção os que se expressavam, identificam situações semelhantes e podem sugerir alternativas para lidar com determinada dificuldade. As sugestões parecem renovar as esperanças de que algo possa ser feito, criam estratégias de apoio e possibilitam compartilhar angústias semelhantes. Quando uma pessoa precisa de uma atenção específica, os coordenadores mostravam as possibilidades dentro do contexto da instituição e fora dela, como a procura por acolhimento personalizado no Escritório de Saúde Mental, pelo aplicativo COMVC, pela busca autônoma por atendimento à comunidade, seguindo os protocolos possíveis do Instituto de Psicologia, do Instituto de Psiquiatria e do Hospital Universitário, que geralmente os participantes desconhecem.

O interesse das Unidades que participaram das Rodas de Conversa se refere a preocupações em relação à saúde mental de estudantes e servidores públicos durante a pandemia. Surtos de natureza psiquiátrica, depressões, ideações ou tentativas de suicídio, isolamento e restrição da circulação social e dificuldades diante das ausências de atividades presenciais são temas que apareceram com frequência nas Rodas de Conversa.

Soma-se a isso os conflitos que ocorrem entre alunos oriundos das escolas públicas e aqueles mais favorecidos econômica e culturalmente; o sofrimento diante da autodeclaração dos pretos, pardos e indígenas e as dificuldades vividas por ele e estudantes trans ou homossexuais de uma unidade de saúde. Esses encontram, na Universidade, uma possibilidade de diálogo distinta ou não experimentada em suas casas ou famílias, e combate aos estigmas e preconceitos diante dos transtornos mentais. As dificuldades com a conexão da internet, também estão presentes apesar do forte investimento da Pró-Reitoria de Pós-graduação e Pró-Reitoria de Graduação para os estudantes que manifestaram esses problemas.

O acolhimento por meio de Rodas de Conversa ao ter como objetivo ser uma proposta educativa e formativa, traz a novidade de reconhecer em cada pessoa a potência do encontro e da 
transformação, como mediadores do cuidado, pois é inerente à vida as possibilidades de ajuda potencializadas por meio do compartilhamento de experiências. As pessoas podem oferecer uma "escutatória" (ALVES, 1991), pois a história de um pode beneficiar muitos. A escuta como forma de cuidado (LEVY, 2020).

As Rodas de Conversa fortalecem relações, propiciam a formação de novos vínculos, a reflexão sobre o trabalho remoto e as dificuldades na vida durante a pandemia. Trabalha-se em relações horizontais e as conversas são mediadas para possibilitar o diálogo com as diferenças e experiências de cada participante. Elas também oferecem oportunidade para lidar com dificuldades que porventura se relacionem com dúvidas sobre evasão, abandono, trancamento de matrículas e dificuldade de preconceitos sociais, raciais e de gênero assim como os estigmas relacionados à saúde mental, além de abordar temas relacionados à formação e cultura com funcionários e professores.

Esse exercício de observação e escuta do outro e de si próprio (ARBEX, 2019) trouxe a campo a importância da sensibilidade nas relações universitárias, o que facilitou o acolhimento e a construção de vínculos por meio do autoconhecimento, do despertar da resiliência emocional e da empatia gerada em cada encontro, mobilizador de questões sociais e emocionais. A abordagem socioemocional gerou uma aprendizagem nesta ampla gama de habilidades que os participantes precisam para definir metas a atingir diante das dificuldades impostas pelas circunstâncias ambientais, gerenciar o próprio comportamento e assim construir relações, lembrando e fazendo circular ideias e informações que se tornaram úteis a cada um.

Após cada Roda de Conversa, a equipe discutia as vivências sentidas e ampliava assim as reflexões sobre a experiência, como um modo de elaborar o ocorrido e avançar no conhecimento gerado pela potencialidade de cada encontro, valorizando aspectos éticos e necessários no enfrentamento das dificuldades impostas pela pandemia Covid-19.

Legitimar o encontro, enquanto reconhecimento de uma comunidade de pertença, em seu sentido genuíno de abertura às diversidades (pois cada um imprime sua marca única por meio da singularidade e carrega a potencia diante dos eventos e no enfrentamento das adversidades) da escuta (em que o confronto de ideias pode ser reconhecido em suas peculiaridade e possibilidade de mudança de perspetivas e compreensões) - e de corresponsabilização (em uma ação equânime capaz de ativar solidariedade e respeito), são reflexões relevantes ao se constituir ações horizontalizadas no cuidado à saúde mental (Cardoso, Silva, 2013).

O reconhecimento da importância de espaços horizontalizados no cuidado recíproco são legitimados através da empatia, em que é possível captar as vivências do outro na corporeidade e na reflexão, tendo cada participante, ainda que singular, como semelhante a si mesmo e ao outro, nem melhor, nem pior, sem competitividades nem julgamentos, possibilitando o resgate do sentido de uma micro-comunidade, que valorou cada gesto individual em gesto comunitário.

Desvelamos necessidades e potencialidades, como a importância de estabelecermos relações entre os sujeitos, pautadas pelo respeito, pela liberdade e pela solidariedade e a legitimação da singularidade como uma característica inerente ao ser humano (SILVA, 2011, p.11).

É importante acrescentar que Rodas de conversa, neste contexto da pandemia, aconteceram exclusivamente na modalidade on-line. Ainda que os alunos tragam como temáticas os desafios das atividades de ensino remotas, cabe-se refletir se o espaço do encontro, mesmo que tecnologicamente mediado, tem sido reconhecido dentre do ensino remoto emergencial.

O uso das tecnologias não pode ser entendido como uma simples transposição das aulas fisicamente presentes às mediadas pela Internet. Acrescenta-se, ainda, a necessidade de reconhecer 
o campo digital como possuidor de suas especificidades, e que demandam compreensões outras pois, embora seja semelhante à modalidade física, carrega suas nuances e desafios que não podem ser naturalizados (Antúnez, Silva, 2021).

A potência do encontro on-line das Rodas de Conversa é visível, seja nas temáticas conversadas pelos grupos homogéneos, e também, na possibilidade de ações de saúde mental no ambiente universitário enquanto estratégias regulamentadas dentro das Faculdades. Os grupos heterogêneos foram relevantes ao possibilitar a horizontalidade das relações entre diferentes grupos, como alunos, funcionários e professores, o que possibilita também o fortalecimento do vínculo, o reconhecimento de estratégias comuns para o fortalecimento do grupo, mas também a possibilidade de promover políticas efetivas a partir da participação dos diversos níveis envolvidos.

\section{Considerações finais}

A partir deste relato de experiência desenvolveremos um projeto de estudo de viabilidade das Rodas de Conversa, que será apresentado como uma proposta ao Comitê de ética em pesquisa com seres humanos do Instituto de Psicologia da Universidade de São Paulo, com previsão de início em agosto de 2021, conduzindo uma intervenção de grupo único com um desenho de pré e pós teste a partir de questionários que avaliam aspectos da saúde mental dos participantes, que serão levantados, discutidos e avaliados em sua pertinência. Questionários respondidos por cada participante para termos outros dados do grupo. Como exemplo:

(...) a Universidade de Harvard introduziu, há quase um século, um método até então empregado no ensino de Direito e Medicina: os estudos de casos. Trata-se de proposta pedagógica que parece atender tanto aos princípios construtivistas de aprendizagem ativa, reflexiva, colaborativa e autenticamente contextualizada, quanto aos desafios do modelo de pensamento complexo" (LIMA, 2003, p.1).

O modelo da intervenção seguirá o relato de experiência apresentada neste artigo. Assim, analisando contextos em que os problemas se apresentam e avaliando as consequências de possíveis intervenções poderemos dessa forma desenvolver a capacidade criativa de imaginar cenários futuros, elaborar soluções inovadoras e sintetizar os resultados obtidos de forma convincente (LIMA, 2002), robusta e baseados em boas práticas.

Uma pergunta norteadora para o estudo de viabilidade será: como as novas tecnologias de comunicação e informação aplicadas às Rodas de Conversa on-line podem contribuir para o processo de fortalecimento de competências e sensibilidades para lidar com a nova realidade híbrida de ensino-aprendizagem na universidade?

Nesta perspectiva, o Escritório de Saúde Mental pretende criar um curso de cultura e extensão universitária com o objetivo de formar profissionais da área de educação, saúde e afins na modalidade de Rodas de Conversa presencial e também através do uso das Tecnologias de Informação e Comunicação (TICS).

\section{Apoio}

FAPESP 2018/19.520-8, CNPq 302417/2018-4, FAPESP 2018/11351-2.

\section{Referências}

ALVES, R. Escutatória. In: R. Alves (Org.), O amor que acende a lua. Campinas: Papirus, 1991. 
Andrés Eduardo Aguirre Antúnez, Ana Luiza Raggio Colagrossi, Erika Rodrigues Colombo, Frida Zoltye

Nara Helena Lopes Pereira da Silva

ANDRADRE, J. L V. et al. "Água de Chocalho" em Rede: Roda de Conversa On-Line Com Famílias de Crianças Autistas Durante A Pandemia de COVID-19. Expressa Extensão, v. 26, n. 1, p. 429-437, 2021.

ANTÚNEZ, A. E. A; SILVA, N.H.L. Consultas terapêuticas On-Line em saúde mental. Santana de Parnaíba: Manole, 2021.

ARBEX, A. L. Assembleias dramatizadas e formação de grupo relatos de experiências com alunos de $2^{\circ}$ s e 3 os anos do ensino fundamental. Revista Construção Psicopedagógica, v. 27, n. 28, p. $48-68,2019$.

ASSIS, A. D. et al. ABRACE - Grupo de acolhimento e cuidado dos estudantes da UFOP. Além dos Muros da Universidade, v. 6, n. 1, p. 44-54, 2021.

BORGES, N. E. H. et al. Conversa na rede. In: 70 Seminário de Educação Profissional e Tecnológica (SEMEPT), 2020, Virtual. In: Anais do 70 Seminário de Educação Profissional e Tecnológica. Bento Gonçalves: Instituto Federal de Educação, Ciência e Tecnologia do Rio Grande do Sul (IFRS), 2020.

COMVC (2020) Importância das Rodas de Conversa. https://m.youtube.com/watch?v=gg_ cYPEvEjE. Acesso em 18/05/2021

COSTA, R. R. O. et al. As rodas de conversas como espaço de cuidado e promoção da saúde mental. Revista de Atenção à Saúde, v. 13, n. 43, 2015.

CRUZ, A. Reitor e vice-reitor apresentam novos projetos para a Universidade. Jornal da USP, São Paulo, 08 de fev. 2018. Disponível em: https://jornal.usp.br/institucional/reitor-e-vicereitor-apresentam-novos-projetos-para-a-universidade/. Acesso em: 10/04/2021

Explore SEL (2020) http://exploresel.gse.harvard.edu. Acesso em: 10/03/2021.

GODSON, S; COMLEY, K-The MeeTwo “Mental Help” Handbook. MeeTwo Education. UK, 2018.

LEVY, A; BIEHL, J; GHODSEE, K; STEVEVENSON, L. On listening as a form of Care. Slought Foundation and Health Ecologies Lab, Philadelphia. USA, 2020.

LIMA, M. C. Estudos de casos hipertextuais: rumo a uma inovação no método Harvard de ensino de gestão. Revista de Administração Contemporânea, v. 7, n. 3, p. 77-99, 2003. Disponível em: https://doi.org/10.1590/S1415-65552003000300005

LIMA, M. Ambientes de aprendizagem organizacional mediados por computador: o projeto aplicado de novas tecnologias para educação on-line. In: CARDOSO, C. (Org.). Comunicação organizacional hoje: novos desafios, novas perspectivas. Salvador: Unibahia, 2002.

MeeTwo Mental Help (2018) https://www.meetoo.help. Acesso em 30/05/2021.

MOURA, A. F.; LIMA, M. G. (2014). A reinvenção da Roda de Conversa: um instrumento metodológico possível. Revista Temas em Educação, v. 23, n. 1, p. 98-106. doi:10.22478/ufpb.2359-7003.

PORTAL DO GOVERNO. Projeto COMVC lança aplicativo para orientação e apoio à saúde mental. Governo do Estado de São Paulo, São Paulo, 24 de jun. 2020. Disponível em: www.saopaulo. sp.gov.br/ultimas-noticias/projeto-comvc-lanca-aplicativo-para-orientacao-e-apoio-asaude-mental/. Acesso em 10 abr. 2021. 
SAMPAIO, J. et al. Limites e potencialidades das rodas de conversa no cuidado em saúde: uma experiência com jovens no sertão pernambucano. Interface-Comunicação, Saúde e Educação, v. 18, p. 1299-1311, 2014.

SILVA, N. H. L. P. Saúde mental na Estratégia Saúde da Família: uma compreensão a partir da Fenomenologia de Edith Stein. 2011. Tese (Doutorado em Psicologia) - Universidade de São Paulo, Ribeirão Preto, 2011. Disponível em: https://teses.usp.br/teses/disponiveis/59/59137/ tde-21102013-151555/pt-br.php. Acesso em: 10 abr. 2021

SILVA, N; H. L. P. CARDOSO, C. L. Contribuições da fenomenologia de Edith Stein para a atualção do psicólogo nos núcleos de apoio à Saúde da Família (NASF). Revista Latinoamericana de Psicopatologia Fundamental, v. 16, n. 2, pp 246-259. 2013. Disponível em <https://doi.org/10.1590/S1415-47142013000200005>.

SOARES, A. B., Gomes, G., Maia, F. A., Gomes, C. A. O., \& Monteiro, M. C. Relações interpessoais na universidade: o que pensam estudantes da graduação em psicologia. Revista Saúde e Pesquisa, v. 9, n. 2, p. 251-262, 2016. Doi: 10.5433/2236-6407.v7n1p56.

SOUZA, D. C. Condições emocionais de estudantes universitários: estresse, depressão, ansiedade, solidão e suporte social. 2017. Dissertação (Mestrado em Psicologia) - Universidade Federal do Triângulo Mineiro, Uberaba, 2017.

VRIES, J. D., HOOFF, M. L. M. V., GEURTS, S. A. E., \& KOMPIER, M. A. J. (2016). Exercise as an Intervention to Reduce Study Related Fatigue among University Students: A Two Arm Parallel Randomized Controlled Trial. PLOS ONE, 11(3), 152-37. Doi:10.1371/journal.pone.0152137.

WARSCHAUER, C. Rodas e narrativas: caminhos para a autoria de pensamento, para a inclusão e a formação. In: PINTO, S. A. M. (Coord.) Psicopedagogia: contribuições para a educação pós-moderna. Petrópolis: Vozes, 2004. 